\title{
DISTANCE EDUCATION IN NURSING
}

\author{
Prof. Annamart MJ Oosthuizen, (University of South Africa);
}

Prof. Gisela H Van Rensburg, (University of South Africa)

\begin{abstract}
The nursing profession is challenged to meet evolving health care needs of populations, while maintaining the standards and integrity of the profession. Limited resources in health care and nursing education compelled the nursing profession to embrace distance education as a way of upgrading the qualifications of large numbers of nurses in a timely manner without disrupting service delivery. All distance education programmes in nursing are post-basic programmes and are presented at certificate, diploma and degree level. Accessibility to higher education for further studies and affordability are primary purposes of distance education programmes for nurses. An increased participation of local and international private higher education institutions in distance education, a diverse body of learners and the impact of technology on teaching, learning and assessment further contributed to a shift in delivery within contact and distance education institutions.
\end{abstract}

The dynamic changes in society demand that qualified people return to higher education to keep abreast with innovation and change. Distance education provides opportunities to combine family and work responsibilities while engaging in continuous professional development. Despite the advantages, distance education in higher education is confronted with challenges that relate to student support, lack of computer literacy and inaccessibility of electronic media and the Internet in some areas. Scientific writing and reading skills, a reading 'culture' and study skil ls are often lacking in the students. Remedial teaching in this regard could be a problem, especially where students do not have easy access to communication media.

Education is a major key to leadership development and the development of the nursing prof ession. The modern knowledge-driven society requires that people upgrade their knowledge and skills in order to remain competitive and competent in a fast-changing environment. Distance education is a suitable way of ensuring opportunities for all to engage in continuous professional development and lifelong learning

Keywords: Distance learning; Education; Nursing

\section{Introduction}

In creating an effective and efficient higher education system, access to education becomes a challenge. To address these challenges various modes of education are necessary to reach a wide and diverse population. Nursing is challenged to meet evolving health care needs, while at the same time maintaining the standards and integrity of the profession. This requires expertise in education in terms of educational resources and accessibility. One way of developing expertise in education is through distance education.

According to Lewis and Farrell (2005:1), countries are embracing distance education as a means of upgrading the qualifications of large numbers of nurses in a timely manner without disrupting their jobs. However, removing nurses from the clinical field, as well as potential nurse leaders and nurse educators from an already limited labour force for the purpose of further education is almost impossible and perhaps immoral. Education through a distance education model is therefore more appropriate. Distance education has been part of higher education in South Africa and globally for many years, beginning with the University 
of South Africa in 1946 (Boucher, 1973: 223; Tait, 2003: 2) and followed in 1969 by the Open University of the United Kingdom (British Open University) (Lewis \& Farrell 2005:1). Distance education refers to any type of instruction in which the student and educator are separated by physical distance, i.e. not in the same room. It is a medium of teaching and learning using modern technology to bridge the distance between teachers or students (O'Lawrence 2007:1). Braimoh (2010: 231) describes it as being a purposef ul learning experience, preparing students to achieve the goal of person-power development without disrupting his/her community, workplace or family members. Jeffries (undated: 4) cites the definition of distance education by Garrison and Shale (1987) which allows flexibility in defining distance education. They suggest that distance education

- implies that the majority of educational communication between educator and student occurs non contiguously;

- involves two-way communication between educator and student for the purpose of facilitating and supporting the educational process; and

- uses technology to mediate the necessary two-way communication.

As early as the 1980s distance education was described as having two forms: the first correspondence based distance education is oriented to independent study, whereas the second offers teaching and learning experiences simultaneously through telecommunication technology (Jeffries, undated: 4).

Although distance education has changed over the years, it is still off ered largely through first- and secondgeneration distance education modes that rely heavily on printed material as the form of information dissemination. This is particularly the case in developing countries (Aluko, Hendrikz \& Fraser 2011:115). It is, however, necessary to adopt a strategic approach for the improvement of academic quality through innovative strategies, acknowledgement of the heterogeneity of the student clientele and continuous professional development of academics involved in distance education.

The purpose of this chapter is to describe the status of programmes offered in South Africa to nursing students through the mode of distance education.

\section{The case for distance education}

The rapid expansion of distance education programmes is influenced by changes in educational philosophy with the massification of higher education, changes in information and communication technology which facilitate the development of new and different modes of delivery, a need for higher cost-efficiency, increased participation of local and international private higher education institutions in distance education and the crucial role of distance education programmes in meeting the challenges of a diverse body of learners to access higher education. The impact of technology on teaching, learning and assessment further contributed to a shift in delivery within contact and distance education institutions. Advances in technology enabled contact institutions to offer programmes in an alternative mode, while such technologies enabled distance education institutions to make regular contact with students through electronic mail, video conferencing and today even via mobile phone.

\section{Advantages of distance learning}

O'Lawrence (2007:5) lists the following advantages for both students and educators:

- Flexibility: students are able to do much of the work at times and places that suit them. 
- It allows students to work and learn at their own pace - within certain limits.

- Where distance learning is combined with traditional (contact) instruction the educator can select which work can be studied by students on their own.

- Students can choose course offerings without the possibility of conflict in timetables.

- In courses with large numbers of students, computer-aided learning tools help achieve a certain level of standardisation.

- It reduces operational costs for institutions. By centralising the development of some of the learning tools, course development costs could be lowered.

\section{Disadvantages of distance learning}

It should be noted that not all students have the sort of personality which enables them to study through the mode of distance education. According to O' Lawrence (2007: 5) the following could impede success for learners studying through distance education:

- Some learners lack self-discipline and time management skills to study independently.

- The expenditure required for computer equipment and Internet connections outweighs the usual expenses of taking a conventional course for some learners.

- Some students feel lonely without face-to-face contact with other students, despite the availability of electronic chat rooms or discussions.

- Technical problems may interrupt the instruction and create confusion and frustration for the educator and students.

- Students could find it difficult to adapt their learning styles to the distance education mode.

\section{Distance education landscape in South Africa}

According to the National Plan for Higher Education (2001: 58), the Council for Higher Education recommends that a single dedicated distance education institution providing innovative and quality programmes especially at undergraduate levels should be established. Opportunities that distance education institutions have created for students in Africa and other parts of the world must be maintain ed and expanded. This recommendation culminated in the establishment of a single dedicated distance education institution through the merger of the University of South Africa, Technikon South Africa and the distance education centre of Vista University. The merger of distance education institutions into one institution happened simultaneously with the mergers of other higher education institutions, thus altering the education landscape in South Africa.

However, the same document (2001: 56) states that the traditional distinction between contact and distance institutions and modes of delivery is becoming increasingly blurred. It is asserted that higher education programmes increasingly exist on a continuum spanning distance programmes on one end and face-to-face programmes on the other. The changing role of distance education provision is evident in the large number of distance education programmes offered by traditional contact universities. Traditionally, distance education was offered through a correspondence model. This approach has changed as a result of developments in distance education and the traditional model is being replaced with a model that incorporates the provision of learner support through a variety of mechanisms, such as learning centres with audio-visual and computer-assisted support. Resource-based learning approaches using multi-media 
delivery modes as part of their traditional contact programmes have been introduced by contact institutions.

In his review of the higher education system in South Africa from 1994-2004, Jansen (2004: 305) proposes that one of the ten most important changes in higher education has been the changing modes of delivery. Before the1990s, higher education institutions acted according to clearly defined roles and offered either contact instruction or correspondence education, based on their specific designation. The two distance education institutions were the University of South Africa (UNISA) and Technikon So uth Africa. During the 1990s, a group of traditionally contact institutions expanded their programmes to incorporate various kinds of distance education, leading to an extensive growth in students studying through distance education modes in these institutions.

In 2002/2003, the Higher Education Quality Committee (HEQC), responded to a concern from the Minister of Education as well as from numerous stakeholders that quality issues in distance education needed to be addressed. Consequently, the South African Institute for Distance Education (SAIDE) was requested to develop a set of strategies for the quality assurance of distance education. One of these strategies was a comprehensive set of criteria for quality distance education agreed by the distance education community. The decision was taken to use the 1998 criteria and revise these in the light of developments in distance education and quality assurance in the intervening years (NADEOSA, 2004). In 2004, the National Association for Distance Education and Open Learning of South Africa (NEDEOSA) published the following quality criteria for distance education in the country:

\section{Policy and Planning}

The educational provider has a clear sense of purpose and direction, which is informed by national priorities as well as by the quality demands of cost-effective educational provision. There is both a rationale and relevant systems for the use of distance education methods to achieve the purpose of the programme for the target learners.

\section{Learners}

There is up-to-date detailed information about past, present and potential learners. This is used to inform policy and planning of programme development, course design and materials development, learner support, and other relevant aspects of educational provision.

\section{Programme Development}

Programmes are flexible and designed in accordance with national needs, as well as the needs of prospective learners and employers. Their form and structure encourage access and are responsive to changing environments. Learning and assessment methods are appropriate to the purpose and outcomes of the programmes.

\section{Course Design}

The course curriculum is well-researched, with aims and learning outcomes appropriate to the level of study. Content, teaching and learning and assessment methods facilitate the achievement of the aims and learning outcomes and there is an identified process of development and evaluation of courses. 


\section{Course Materials}

The content, assessment, and teaching and learning approaches in the course materials support the aims and learning outcomes. The materials are accessibly presented, teach in a coherent way that engages the learners and there is an identified process of development and evaluation of course materials.

\section{Assessment}

Assessment is an essential feature of the teaching and learning process, is properly managed, and meets the requirements of accreditation bodies and employers.

\section{Learner Support}

Learners are provided with a range of opportunities for real two-way communication through the use of various forms of technology for tutoring at a distance, contact tutoring, assignment tutoring, mentoring where appropriate, counselling (both remote and face-to-face), and the stimulation of peer support structures. The need of learners for physical facilities and study resources and participation in decisionmaking is also taken into account.

\section{Human Resource Strategy}

The staff structure, as well as the experience, qualifications, responsibilities and job descriptions of staff are appropriate for the education and training services provided and staff development programmes equip staff to perform their roles and tasks effectively.

\section{Management and Administration}

There is effective and accountable management of communication and information as well as human and material resources. Democratic governance structures are in place while efficient administrative systems support the activities of the educational provider who is financially sound and can make reliable educational provision.

\section{Collaborative Relationships}

In the interests of cost-effective provision of education and training, collaborative relationships are formed and collaborative projects are undertaken wherever possible.

\section{Quality Assurance}

There is an integrated framework at a policy and practice level that informs a clear cycle of planning, implementing, monitoring, reflection and action to ensure that learners' and staff needs, as well as the needs of other clients, are met.

12. Information Dissemination

Education and training services of the educational provider are effectively and accurately promoted in a variety of ways.

\section{Results}

The educational provider fulfils its mission and individual programmes achi eve valid teaching and learning goals in cost-effective ways that have a positive impact on society and meet the needs of clients and national priorities. 


\section{Distance education programmes in nursing}

Basic (pre-service) nursing education is a four-year comprehensive course regulated by R425, as promulgated through the Nursing Act 50 of 1978 offered by colleges and universities. Students who successfully complete basic degrees and diplomas are registered by the South African Nursing Council (SANC) as general nurses, midwives, psychiatric and community health nurses. Basic nursing education is not offered through the mode of distance education: students attend classes, are accompanied by educators in the practical field and are required to complete a prescribed number of hours in the clinical environment.

Once registered as professional nurses with the SANC, nurses can follow post-basic programmes to specialise in various fields. Post-basic programmes are offered at contact institutions solely through contact teaching modes, combined contact and distance education modes (blended education) or as complete distance education programmes at contact institutions and UNISA. Post-basic distance education programmes can lead to certificates, diplomas, postgraduate diplomas, honours', master's and doctoral degrees. Ehlers (2002: 209) states that distance education programmes enable many nurses to improve their qualifications without leaving their jobs and families. Nurses can therefore prepare themselves through distance education programmes to become specialist nurses, nurse managers or nurse educators from undergraduate to doctoral level.

Seloilwe (2005: 571) supports distance education programmes for nurses and argues that, in a globalised world, educational programmes should become more universal so as to cater for a more diverse student body. Distance education enables nursing students to access programmes at a 'distance' -locally, nationally and internationally.

\section{Current status of distance education in nursing}

The following discussion is based on an analysis of data collected from the universities in South Africa in 2011. A structured questionnaire consisting of twelve items was distributed electronicall $y$ to all the nursing departments. Nursing colleges and schools which do not offer distance education programmes due to their educational mandate to present clinical programmes were therefore not included in the investigation. Of the 22 universities with nursing departments, four currently present programmes through distance education. Of these four universities, only one (UNISA) is a designated distance education institution. The other three universities are contact universities. None of the Universities of Technology have distance education programmes. In some instances, contact universities provide decentralised rather than distance education programmes, since educators offer face-to-face courses at decentralized venues.

All distance education programmes are post-basic programmes and are presented at certificate, diploma and degree level. The certificate programme that was reported is an advanced university certificate in wound care.

Diploma programmes are either advanced university diplomas or postgraduate diplomas that lead to qualifications in:

- Nursing education/health sciences education (3 universities); 
- Nursing management/health services management (3 universities);

- Community nursing (2 universities);

- Clinical nursing science, health assessment, treatment and care (2 universities).

Baccalaureus degree programmes for registered nurses offered through distance education lead to qualifications in:

- Nursing education/health sciences education;

- Nursing management/health services management;

Master's programmes include:

- Master's in Public Health, which is open to other health-related disciplines as well;

- Master's degree in Nursing.

All doctoral programmes in South Africa follow the British model with no course work, but an extensive supervised research project. Such research-oriented doctoral programmes in which students are expected to work independently with minimum guidance from supervisors can be done successfully on a distance education basis.

Although a number of undergraduate programmes are offered, the main focus was identified as being the postgraduate programmes (master's and doctoral programmes).

\section{Rationale for having programmes through distance education}

All universities which present distance education programmes agree that the accessibility to higher education for further studies whilst being employed and not necessarily living in close proximity to a contact university is the main purpose for presenting programmes through this mode. This might be particularly important in the nursing profession, which is predominantly a female profession, where their role as wives and mothers might make it more difficult for them to leave home for professional reasons.

However, three of the universities have on-site support programmes and pre-scheduled contact sessions with a module manager or module facilitator for these students. These support programmes include group discussions, video conferences, computer training for students, using e-learning platforms effectively and skills in accessing information through different methods. Darrell, Cain, Marrara, Pitre and Armour (2003: 48) found that students seem to be disengaged from, and sometimes unaware of, the support services available to them. They speculate that this could be due to the students' prior experience with higher education or undergraduate studies, limiting a need for support. In a South African study by Mash, Marais, Van der Walt, Van Deventer, Steyn and Labadarios (2006: e6) it was found that learning styles of students in Nursing Sciences studying through distance education differed, and some avoided interaction via technology, yet they appreciated face-to-face and other interaction with other students.

Accessibility further refers to the social responsibility towards Africa and other countries. According to the mandate of the National Plan for Higher Education (2001: 58), UNISA, as designated distance education institution, must provide opportunities to students in Africa and other parts of the world to access higher education. 
Affordability is another major advantage in that students can continue earning a salary, live in the place of their choice and register for the number of modules based on available funds. O'Lawrence (2007: 4) confirms that adult learners are attracted to distance education because they receive salaries, salary increases and promotion while studying.

Social advantages of distance education include the ability to combine family responsibilities with studies, especially for non-traditional students such as parents raising children and older persons returning to higher education for continuous professional development. The dynamic changes in society demand that qualified people return to higher education to keep abreast with innovation and change. Mash et al (2006: e6) confirm that students in Nursing Sciences studying through distance education at a South African university find it easier because they can determine their own time schedules.

The rationale for presenting the certificate programme in wound care through distance education is the limited number of universities presenting this programme. This enables students from all over the country to enrol for the programme. This means that limited human resources in smaller niche programmes might make it necessary to limit the number of centres offering the programmes. Making them available through the distance education mode is therefore essential to ensure accessibility to people from all over the country.

\section{Target group}

Universities reported the target group as ranging from registered nurses within the public sector to private sector institutions in South Africa, Africa and other countries.

\section{Strategies and tools used in teaching through distance education}

The strategies and tools used to teach nursing programmes in the distance education programmes in South Africa are multiple. These include printed material in the form of study guides, workbooks, tutorial letters and submission of portfolios. Electronically supported means of teaching and learning incl ude DVD, CDROM, audio or videotapes, interactive telematic broadcasts and the Internet. Although the mode is distance education, some programmes require compulsory and optional contact sessions. These sessions include group discussions, simulated teaching practice, management workshops and decentralised block sessions. The ratio of face-to-face and distance education in these programmes is not known.

Mash, Marais, Van der Walt, Van Deventer, Steyn and Labadarios (2005: 1097) evaluated different teaching strategies used by lecturers in distance education programmes at one of the South African universities offering nursing programmes through this mode and found that during interactive television sessions the students held predominantly passive roles and lecturers were more active and dominant, giving direct instructions and asking questions to which students replied. Although described as distance education, the structure reflects a more traditional classroom or didactic style of teaching and learning.

\section{Positive experiences of distance education}

The fact that large numbers of students from a wide geographical area (nationally and globally) can register for programmes offered through distance education is regarded as one of the most important advantages. In South Africa, students from deep rural, rural and urban areas all over the country have the opportunity to further their studies or enrol for programmes that are only offered by one or two universities, such as the certificate in wound care. In an article on te acher education in South Africa, Mashile (2008: 362) argues that 
the focus of a profession should not only be on supply and demand but also on retention. Well-qualified nurses have a wider range of employment opportunities which reduces unemployment or vacancies in health-related posts. In turn, a stronger workforce addresses the health needs of the community.

In distance education, students can manage their educational programme in terms of study period and time. A degree course can be structured in such a way that it accommodates individual situations and needs. Students decide to register for a certain number of modules based on their available time and funding. They can study at their own pace and according to their own learning styles. To prevent isolation, students often form study groups without necessarily having to live in the same proximity. These study groups can be electronic groups such as those at UNISA.

Where distance education universities have options of contact sessions, these are regarde $d$ as positive, motivating and supportive. It is very important that universities expand the support available for students studying through distance education. Tait (2003: 4) found that student support in the form of guidance and counselling, tutor support and effective administrative and information systems reinforces student confidence, self-esteem and progress and reduces the drop-out of students studying through this mode. Educators also regard the opportunity to give personal and 'direct' feedback to students as an additional advantage. The guidance provided to students during contact sessions could clarify uncertainty, solve problems and serve as motivation.

Apart from the discipline-specific knowledge that students gain through their studies, they also develop skills in technology and e-learning. Using the various forms of media and the Internet are not necessarily skills that all students from South Africa have. This was confirmed in the study by Mash et al (2006: e5) who found that technophobia was rife among distance students at one of the South African universities, with nursing students reporting that their experience with interactive TV was terrifying and stressful to the extent that they did not log on for fear of being asked questions by the lecturer.

\section{Challenges of distance education}

Student support remains a huge challenge in higher education and more specifically in distance education. A lack of computer literacy and inaccessibility to electronic media and the Internet slows down the teaching process in that communication with students could be hampered. To address this challenge, two institutions established satellite campuses or regional offices where students could have access to computers. Three universities also address these issues during contact sessions with students.

In distance education, establishing and building effective communication between educators and students has to be initiated through the written word. Maintaining communication can be challenging if the means are not conducive to doing so. Possible ways to support effective and efficient communication are paperbased notices, electronic posts on e-learning platforms such as cell phone text messages, podcasts and video clips. This affords the student the opportunity to access additional information in their own time.

Scientific writing and reading skills, a reading 'culture' and study skills are often lacking in the students. Remedial teaching in this regard is a problem, especially where students do not have easy access to the electronic media such as e-mails through which a faster way of communication can be established. 
Postal services do not always function optimally and affect the time of delivery. Study material reaches students late and, in turn, assignments are received after crucial closing dates. This could result in students not meeting the requirements of the module or programme.

The expectations of students regarding the role of the educator resulted in additional support structures and services being developed to assist students to become independent learners. Due to the large number/high volume of students enrolling at distance education institutions, staff burn-out becomes an occupational risk which could affect the throughput of students. Due to problems related to quality assurance, some programmes that were previously offered through the mode of distance education were terminated. One university, which had satellite campuses in other cities as far as $500 \mathrm{~km}$ away, terminated those programmes for the following reasons: they were costly in terms of human resources, distance to travel and support services for students. In addition, difficulties related to manageme nt of tests and examinations, and problems with technology contributed to the termination of the programmes. Finding qualified, experienced, willing and able preceptors is a difficult task. This is especially a problem where a programme has a major clinical component.

\section{Conclusion}

Education is a major key to leadership development and the development of the nursing profession. This education must be appropriate to move nursing from models suited to the industrial age to those compatible with the information age in which we now live. Distance education could provide a solution to this problem (Lewis \& Farrell 2005: 5) as it has played a substantial role in the development of nurse educators and nurse managers in South Africa and Africa. Various collaborative efforts between South African universities and African universities, education departments and ministries have seen a number of black nursing leaders and educators from Botswana, Zimbabwe, Zambia, Swaziland, Lesotho, Malawi, Angola and Ethiopia obtaining their master's and doctoral degrees from South African universities.

Distance education could embrace change in the educational field that is dynamic and transformative. Educators in distance education must be ready and willing to learn new and innova tive ways of optimising learning and outcomes of education, but should also be prepared consciously to unlearn the old ways of doing things. The modern knowledge-driven society requires that people upgrade their knowledge and skills in order to remain competitive and competent in a fast-changing environment. Distance education is a suitable way of ensuring opportunities for all to engage in continuous professional development and lifelong learning.

\section{References}

Aluko, R.F., Hendrikz, J. \& Fraser, W.J. 2011. Transactional distance theory and total quality management in open and distance learning. Africa Education Review 8 (1): 115-132.

Boucher, M. 1973. Spes in Arduis. 'n Geskiedenis van die Universiteit van Suid Afrika. Pretoria: Universiteit van Suid Afrika. 
Braimoh, D. 2010. Revisiting lifelong learning for quality improvement in ODL institutions in Africa. Africa Education Review 7 (2): 229-243.

Cain, D.L., Marrara, C., Pitre, P.E. and Armour, S. 2003. Support services that matter: an exploration of the experiences and needs of graduate students in a distance learning environment. Journal of Distance Education 18 (1): 42-56.

Chisolm, L. (ed.). 2004. Changing class: education and social change in post-apartheid South Africa. Cape Town: HSRC Press.

Ehlers, V.J. 2002. Nursing education in the Republic of South Africa. Nurse Educator 27 (5): 207-209.

Jansen, J.D. 2004. Changes and continuities in South Africa's higher education system, 1994 to 2004, in Chisholm, L. (ed.). Changing class: education and social change in post-apartheid SouthAfrica. Cape Town: HSRC Press: 293-314.

Jeffries, M. Undated. The history of distance education. Retrieved from http://www.digitalschool.net/edu/DL_history_mJeffries.htm/ on 18 October 2011.

Lewis, JM \& Farrell, M. 2005. Distance education: a strategy for leadership development. Nursing Education Perspectives 26(6):1. Retrieved from http://www.freepatentsonline.com/article/Nursing-EducationPerspectives/140144483. html on 18 October 2011.

Mash, R.J., Marais, D., Van der Walt, S., Van Deventer, I., Steyn, M. and Labadarios, D. 2005. Assessment of the quality of interaction in distance learning programmes utilising the Internet (WebCT) or interactive television (ITV). Medical Education 39: 1093 -1100.

Mash, B., Marais, D., Van der Walt, S., Van Deventer, I., Steyn, M. and Labadarios, D. 2006. Assessment of the quality of interaction in distance learning programmes utilising the Internet or interactive television: perceptions of students and lecturers. Medical Teacher 28 (1): e1-e9.

Mashile, E.O. 2008. Supply and demand for teachers: is open and distance learning an answer? Africa Education Review 5 (2): 351-363.

National Association for Distance and Open Learning in South Africa (2005). Designing and delivering distance education: quality criteria and case studies from South Africa. http://www.nadeosa.org.za/Activities/QualityCr Accessed on 06December 2011.

National Plan for Higher Education. 2001. http://chet.org.za/manual/media/files/chet hernana docs/South\%20Africa/National/National\%20Plan\%20 for\%20HE\%20SA.pdf Accessed on 20 October 2011. 
Trends in Nursing Vol. 1, Issue 1, $201 \quad$ http://fundisa.journals.ac.za http://dx.doi.org/10.14804/1-1-19

O'Lawrence, H. 2007. An overview of the influences of distance learning on adult learning. Journal of Education and Human Development 1(1). http://www.scientificjournals.org/journals2007/articles/104l.htm Accessed on 18 October 2011.

Seloilwe, E.S. 2005. Globalization and nursing. Journal of Advanced Nursing 50 (6): 571.

Tait, A. 2003. Reflections on student support in open and distance learning. International Review of Research in Open and Distance Learning 4 (1):1-9.

Welch, T. and Reed, Y. (eds). 2004. Designing and delivering distance education: quality criteria and case studies from South Africa. Pretoria: National Association for Distance Education and Open Learning of South Africa. 